\title{
BMJ Open Assessment of the effects of decision aids about breast cancer screening: a systematic review and meta-analysis
}

\author{
Montserrat Martínez-Alonso, ${ }^{1,2}$ Misericòrdia Carles-Lavila, ${ }^{2,3,4}$ \\ Maria José Pérez-Lacasta, ${ }^{2,3}$ Anna Pons-Rodríguez, ${ }^{5}$ Montse Garcia, ${ }^{6}$ \\ Montserrat Rué, ${ }^{1,2,3,7}$ on behalf of the InforMa Group
}

To cite: Martínez-Alonso M, Carles-Lavila M, Pérez-

Lacasta MJ, et al. Assessment of the effects of decision aids about breast cancer screening: a systematic review and meta-analysis. BMJ Open 2017;7:e016894. doi:10.1136/ bmjopen-2017-016894

- Prepublication history and additional material for this paper are available online. To view these files, please visit the journal online (http://dx.doi org/10.1136/bmjopen-2016014238).

Received 17 March 2017 Revised 27 July 2017 Accepted 27 July 2017

\section{CrossMark}

${ }^{1}$ Department of Basic Medical Sciences, University of LleidaIRBLLEIDA, Lleida, Spain

${ }^{2}$ Research Group on Economic Evaluation and Health (GRAES), Reus, Spain

${ }^{3}$ Department of Economics, University Rovira i Virgili, Reus, Spain

${ }^{4}$ Research Centre on Industrial and Public Economics (CREIP), Reus, Spain

${ }^{5}$ Lleida Biomedical Research Institute (IRBLLEIDA), Lleida,

Spain

${ }^{6}$ Cancer Prevention and Control Program, Catalan Institute of Oncology-IDIBELL, L'Hospitalet de Llobregat, Spain

${ }^{7}$ Health Services Research on Chronic Patients Network (REDISSEC), Madrid, Spain

Correspondence to Professor Montserrat Rué; montse.rue@cmb.udl.cat

\section{ABSTRACT}

Objective The aim of this systematic review and metaanalysis of randomised controlled trials (RCTs) and observational studies is to assess the effect of decision aids (DAs) in women aged 50 and below facing the decision to be screened for breast cancer.

Setting Screening for breast cancer. Intervention DAs aimed to help women make a deliberative choice regarding participation in mammography screening by providing information on the options and outcomes.

Eligible studies We included published original, non-pilot, studies that assess the effect of DAs for breast cancer screening. We excluded the studies that evaluated only participation intention or actual uptake. The studies' risk of bias was assessed with the Cochrane Collaboration's tool for RCTs and the National Institutes of Health Quality Assessment Tool for non-RCTs.

Primary and secondary outcomes The main outcome measures were informed choice, decisional conflict and/ or confidence, and knowledge. Secondary outcomes were values, attitudes, uncertainty and intention to be screened. Results A total of 607 studies were identified, but only 3 RCTs and 1 before-after study were selected. The use of DAs increased the proportion of women making an informed decision by $14 \%, 95 \% \mathrm{Cl}(2 \%$ to $27 \%)$ and the proportion of women with adequate knowledge by $12 \%$, $95 \% \mathrm{Cl}(7 \%$ to $16 \%)$. We observed heterogeneity among the studies in confidence in the decision. The metaanalysis of the RCTs showed a significant decrease in confidence in the decision and in intention to be screened. Conclusions Tools to aid decision making in screening for breast cancer improve knowledge and promote informed decision; however, we found divergent results on decisional conflict and confidence in the decision. Under the current paradigm change, which favours informed choice rather than maximising uptake, more research is necessary for the improvement of DAs.

\section{INTRODUCTION}

In Western countries, screening for breast cancer (BC) spread during the 1990s. There was a general consensus on the benefits of screening since several clinical trials in the USA and Northern Europe estimated a

\section{Strengths and limitations of this study}

- This is the first systematic review focused in the impact of decision aids (DA) about breast cancer screening on informed choice, decisional conflict, knowledge, values, attitudes and intention to be screened.

- The review focused on studies that assess DAs designed to inform and help women to decide, not on those aimed at encouraging participation and adherence.

- A limitation of the review is the reduced number of studies included, which can be explained by the recent development of DAs for breast cancer screening.

- There was variability in the type and amount of information included in the DAs and also in the information given to the control group; this variability may explain part of the significant heterogeneity in all the outcomes evaluated.

- The DAs were designed in Australia, the USA and Germany, and women included had higher education levels than women in the general population, limiting the generalisability of the results.

statistically significant and clinically relevant reduction in mortality from $\mathrm{BC} .{ }^{1}$ But in the year 2000 the systematic review from Gotzsche and Olsen started a hot debate, still alive, on the relevance and magnitude of benefits and harms of BC screening. ${ }^{2}$

More than two decades after the introduction of BC mass screening, the evidence on the harm-benefit balance remains inconclusive. On the one hand, advances in adjuvant treatments, a multidisciplinary approach for BC treatment and earlier identification of symptoms by women have diminished the impact of screening on BC mortality reduction. ${ }^{3-5}$ On the other hand, the evidence on adverse effects of screening, characterised by a high consensus on the risk of false-positive results and lack of agreement on the size of overdiagnosis and overtreatment, 
shows that the potential harms of screening are not insignificant. ${ }^{6-8}$

The current prevailing paradigm, which encourages participation, is changing. Two proposals are gaining strength. First, the need to inform women of potential benefits and harms of screening. Some propose not devoting more energy to increasing participation, but dedicating it to informing women to help them make the best decision based on their preferences and values. ${ }^{9-12}$ Second, customising the screening strategies to individual risk. Some recent studies ${ }^{13-15}$ based on mathematical models suggest that risk-based screening may increase benefits and reduce harms. The literature shows that both proposals are gaining strength. ${ }^{16} 17$

Decision aids (DAs) are instruments that communicate evidence-based information on the benefits and harms of different healthcare options to help people make informed choices. The Stacey et al work, ${ }^{18}$ a recently updated Cochrane systematic review on DAs for people facing treatment or screening decisions, included 105 published randomised controlled trials (RCTs) of DAs, 26 of which dealt with cancer screening (13 prostate, 10 colon, 2 breast and 1 cervix) and 4 on BC genetic testing. The authors concluded that, compared with usual care, DAs increase participants' knowledge, objectively measured. In addition, people exposed to DAs feel more knowledgeable, better informed and clearer about their values, and they probably have a more active role in decision making and more accurate risk perceptions. In addition, Stacey et $a l^{18}$ think that more research is needed on their effects on adherence to the chosen option, cost-effectiveness and use with lower literacy populations.

Information on cancer screening is often biased, incomplete and persuasive. ${ }^{19}$ Some leaflets mention the possibility of harms, however they do not quantify them. In Europe, some organisations are providing information on benefits and harms of BC screening, in particular, estimates of mortality reduction, and the frequency of false-positive results of mammography and invasive tests (eg, Cochrane Collaboration, UK NHS Breast Screening Programme; German Institute for Quality and Efficiency in Health Care; Fundació Lliga per a la Investigació i Prevenció del Càncer and Agència de Salut Pública de Barcelona, in Catalonia (Spain)). Information on overdiagnosis appears in some of the information materials. Two recent studies ${ }^{1120}$ have compared the impact of adding information on overdiagnosis to support informed choice on BC screening. In preparation for a RCT on the effect of a DA in mass screening in two regions of Spain, we aimed to identify and summarise all the studies reporting the description and assessment of a DA when applied to women aged 50 and below facing the decision to be screened with mammography in a population-based screening or opportunistic case-finding framework. We expected to find that DAs improve knowledge of options, benefits and harms; create accurate perceptions of benefits and harms; reduce decisional conflict; and enhance informed choice.
METHODS

\section{Eligibility criteria}

Types of studies

We included all the published studies with RCT or beforeafter designs that compared a DA to no intervention, usual care or alternative interventions. The search date upper limit was 31 December 2016. Pilot studies were excluded.

\section{Types of participants}

Participants were women facing decisions about screening in a population-based screening or opportunistic casefinding framework within the age interval of recommended mammography screening. We excluded studies aimed at elderly women only, and studies where participants were asked to make hypothetical choices.

\section{Types of interventions}

DAs were defined as interventions aimed to help women make a deliberative choice regarding participation in mammography screening, by providing information on the options and outcomes. We excluded studies aimed at increasing participation or promoting adherence, and studies not carried out in the context of women facing a real decision.

\section{Types of outcome measures}

The primary outcomes were: informed choice based on values, decisional conflict and/or confidence, and knowledge. The secondary outcomes included: values and/or attitudes towards screening, proportion remaining undecided and proportion reporting intention to be screened.

\section{Language}

We included articles reported in any language.

\section{Information sources}

\section{Search methods for identification of studies}

The search strategy was performed in MEDLINE and SCOPUS and adapted and replicated in EMBASE, CINAHL, PsycINFO and the Cochrane Library Plus. The search included the keywords 'breast cancer' and 'decision' (or 'choice') and 'aid' (or 'informed') and 'mammography' (or 'mammogram'), within the paper title or the abstract. It excluded the keyword 'protocol' from the paper titles and allowed synonyms and free suffixes and prefixes. The reviews identified by this search, as well as the references that they included, were exhaustively used to refine the search strategy to ensure that all the possible relevant references for our review were identified (see online supplementary appendix 1 ).

\section{Study selection and synthesis of results}

All the studies satisfying the inclusion criteria regarding design, participants and interventions were included in this review. Selection and the assessment of risk of bias was independently conducted in pairs by four reviewers (MCL, MJPL, MMA and MR). In the case of disagreement, studies were discussed by the whole team of reviewers until an agreement was reached. 


\section{Data extraction}

The data extraction for the selected studies was independently conducted by two reviewers (MMA and MR) and a consensus version was obtained. In the case that the necessary data were not provided in the articles, the corresponding authors were contacted.

\section{Risk of bias of individual studies}

For the risk of bias assessment, we used the Cochrane risk of bias tool for RCTs and the National Institutes of Health quality assessment tool for non-RCTs. ${ }^{21}$ In case of non-RCTs, the selection, allocation and blinding assessments were not applicable. Sampling bias (a problem for external validity) was assessed in all the included studies.

The risk of bias (low, unclear or high) was assessed considering the study design and the methodological quality of the studies. Data consistency was rated as no inconsistency, inconsistency present or not applicable if there was only one study available, considering each outcome's direction, magnitude and statistical significance over the set of included studies. The assessment methods followed the AHRQ 'Methods Guide for Effectiveness and Comparative Effectiveness Reviews' (www.effectivehealthcare.ahrq.gov/) and were in accordance with the PRISMA (Preferred Reporting Items for Systematic Reviews and Meta-analyses) checklist. $^{22}$

\section{Analysis of results}

For each endpoint of interest, the decision to combine the results of the selected studies in a meta-analysis was based on the heterogeneity of patient populations and interventions, as well as on the methodological heterogeneity of study designs and reported outcomes. Consistency and heterogeneity of the studies' results were assessed with the $\mathrm{I}^{2}$ index and the $\mathrm{Q}$ test, respectively.

If comparable measures were obtained, we pooled the data for the outcomes. To facilitate the data pooling, scores with different ranges (minimum and/or maximum values) were standardised to range from 0 to 100 points. We estimated a weighted effect intervention (with $95 \%$ CI) as the difference between the intervention and control groups in experimental designs, and as changes from baseline assessed in outcome measures postintervention in beforeafter studies. Mean differences or pooled relative risks were estimated for continuous or dichotomous outcomes, respectively. The summary effects of the intervention were obtained using random effects meta-analysis. An additional meta-analysis of the RCTs was performed. We used the library metafor of the R package. ${ }^{23}$

\section{RESULTS}

\section{Study selection}

In total, we identified 607 unique citations from the electronic database searches. Of these, only 14 were selected for evaluation of the inclusion and exclusion criteria. Figure 1 presents the flow chart of the study selection process. Ten studies were excluded after full text assessment (see table A2.1 in online supplementary appendix 2 for details). Finally, three randomised controlled studies (Mathieu et al, ${ }^{24}$ Gummersbach $e t a l^{20}$ and Hersch $e t a l^{11}$ ) and one before-after study (Eden $e t a t^{25}$ ) were selected. These four studies involved a total of 1650 participants from four countries (two from Australia, one each from Germany and the USA).

\section{Study characteristics}

Table 1 presents the studies' characteristics. Gummersbach and Hersch compared two DAs with information about the benefits and harms of mammography screening, providing the intervention group with more complete information. Whereas Gummersbach added more critical information on the harms of screening mammography in the intervention group, the DA in Hersch only differed in providing thorough information of overdetection or not. In contrast, Mathieu compared a DA with receiving no information, and Eden assessed changes after providing a DA. It is important to notice that whereas Hersch and Gummersbach targeted women who were approaching 50 and deciding whether to screen as per their national programme, Mathieu included younger women considering whether to start screening in their 40s, before the recommended age of 50 in Australia. Participants' characteristics are shown in table 2. Means of age were located in the $40-50$ years interval. There are differences between studies in the prevalence of previous mammograms and in education level.

\section{Risk of bias in the included studies}

The evaluation of the risk of bias for the RCTs included the assessment of bias in selection, performance, detection, attrition, reporting, sampling or any other source of bias. Details on the authors' judgement and rationale for risk of bias can be found in tables A2.2-A2.5 (online supplementary appendix 2). The majority of assessed criteria were judged as low risk. Hersch et $a l^{11}$ was the only study free of a high risk of bias in all the domains assessed. Gummersbach et $a t^{20}$ was rated as having a high risk of attrition bias due to a high level of non-response. Mathieu et $a l^{24}$ was rated as having an unclear risk of allocation concealment and also of selective reporting. Eden et $a l^{25}$ included a small sample of women with greater than a high school education, in a single rural geographical area. Therefore, the sample representativeness was limited.

\section{Main outcomes}

Tables 3 and 4 present the risk differences for the dichotomous outcomes and the mean differences for the continuous outcomes, respectively. Figures 2 and 3 show the results of the meta-analyses for the dichotomous and continuous outcomes, respectively. The results of the meta-analysis performed exclusively on the RCTs are presented in table A3.1, online supplementary appendix 3 .

\section{Informed choice}

The DAs increased the proportion of women making an informed decision, $58.0 \%$ vs $36.5 \%$ according to Mathieu 


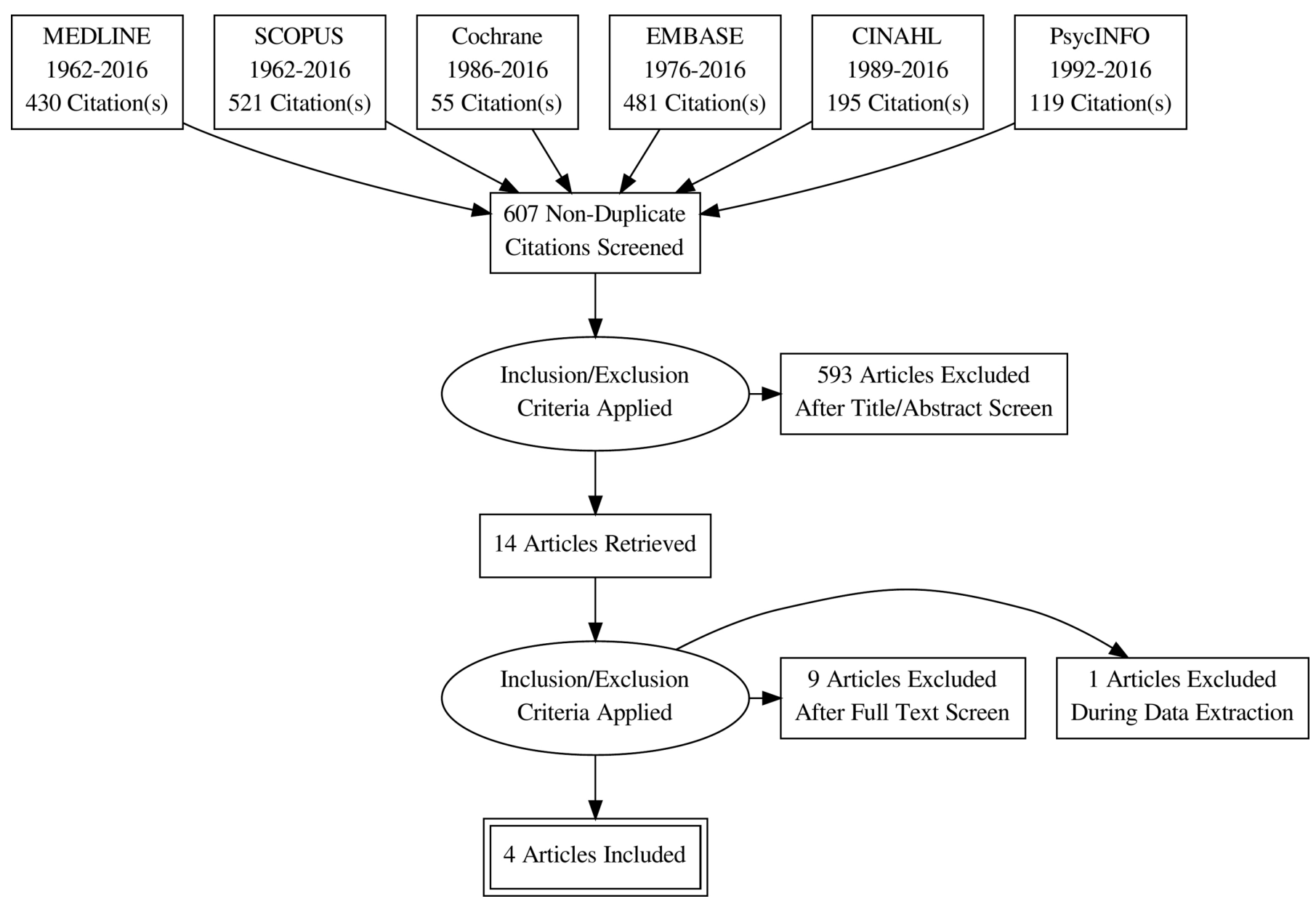

Figure 1 Study flow diagram.

$(\mathrm{p}<0.001)$ and $24.2 \%$ vs $15.4 \%$ according to Hersch $(\mathrm{p}=0.002)$. The meta-analysis estimation of risk difference was $14 \%, 95 \%$ CI ( $2 \%$ to $27 \%$ ) (table 3 and figure 2 ).

\section{Decisional conflict and/or decisional confidence}

Eden observed a significant postintervention decrease in decisional conflict and a significant increase in decisional confidence (table 4, figure 3). In contrast, Hersch noted no significant effect of the intervention on decisional conflict and a significant decrease in decisional confidence, observed also by Gummersbach. These contradictory results introduced high heterogeneity that increased the uncertainty about the overall impact of a DA on decisional conflict and/or confidence (figure 3). The meta-analysis of the RCTs showed a significant decrease in the confidence scale (table A3.1, online supplementary appendix 3 ).

\section{Knowledge}

The use of a DA increased knowledge according to all studies, although the positive difference was not statistically significant in the Gummersbach study (tables 3 and 4). The overall results provided by the meta-analyses were statistically significant, either in the proportion of women with adequate knowledge, with a significant increase of $12 \%, 95 \%$ CI ( $7 \%$ to $16 \%)$, or in the mean score, with a difference of 0.70 out of 10 points, $95 \%$ CI ( 0.27 to 1.13 ) (figures 2 and 3).

\section{Secondary outcomes}

The high heterogeneity of the results did not make it possible to reach conclusions about significant postintervention changes or differences in secondary outcomes, such as positive attitudes and values towards screening, decisions about screening and intention to be screened (table 3, figure 2). The results of the meta-analysis performed exclusively on the RCTs are presented in table A3.2, online supplementary appendix 3 .

\section{Positive attitudes/values towards screening}

Mathieu did not show any significant difference in attitudes, but Hersch obtained a significantly lower frequency of women with positive attitudes towards screening among women receiving the DA with overdiagnosis information.

\section{Undecided about BC screening}

Mathieu reported a significant decrease in the frequency of women undecided about BC screening after the DA administration. In contrast, Hersch obtained a significant increase for the intervention group, with the DA including thorough overdiagnosis information. 
Table 1 Description of the studies' characteristics

\begin{tabular}{|c|c|c|c|c|}
\hline Study & Design & Age group & Exclusion criteria & Decision aid (DA) \\
\hline Mathieu et $a l^{24}$ & $\begin{array}{l}\text { Randomised } \\
\text { controlled } \\
\text { study, } \\
\text { pragmatic* }\end{array}$ & $38-45$ & $\begin{array}{l}\text { Personal history of breast cancer } \\
\text { (BC) }\end{array}$ & $\begin{array}{l}\text { Web-based DA, information on possible } \\
\text { screening outcomes and worksheet to } \\
\text { help weigh up and clarify preferences. } \\
\text { Intervention group: immediate access; } \\
\text { control group: delayed access after } \\
\text { completing the outcome measures. }\end{array}$ \\
\hline $\begin{array}{l}\text { Gummersbach } \\
\text { et }\left.a\right|^{20}\end{array}$ & $\begin{array}{l}\text { Randomised } \\
\text { controlled } \\
\text { study, primary } \\
\text { care based }\end{array}$ & $48-49$ & None & $\begin{array}{l}\text { Mailed leaflet, more informative (especially } \\
\text { on overdiagnosis) for the intervention group. } \\
\text { The leaflet was not created in accordance } \\
\text { with published criteria for evidence-based } \\
\text { patient information, but it contained much } \\
\text { more information relevant to decision making } \\
\text { than the leaflet of the control group. }\end{array}$ \\
\hline Hersch et al ${ }^{11}$ & $\begin{array}{l}\text { Randomised } \\
\text { controlled } \\
\text { study, } \\
\text { community } \\
\text { based }\end{array}$ & $48-50$ & $\begin{array}{l}\text { Personal or strong family } \\
\text { history of } \mathrm{BC}, \mathrm{BC} \text { risk higher } \\
\text { than average, mammography } \\
\text { in the past } 2 \text { years, non-English } \\
\text { speaking }\end{array}$ & $\begin{array}{l}\text { Mailed DA, outcomes assessed by phone } \\
\text { interview. Evidence-based explanatory and } \\
\text { quantitative information on overdiagnosis, } \\
\text { BC mortality reduction, and false positives } \\
\text { for the intervention group versus information } \\
\text { on BC mortality reduction and false positives } \\
\text { for the control group. }\end{array}$ \\
\hline
\end{tabular}

${ }^{*}$ The trial was advertised on the media. Women had free access to the site for eligibility assessment.

†Breast cancer risk based on the B-RST (Breast Cancer Genetics Referral Screening Tool).

Intention to be screened

Hersch noted a statistically significant decrease in the intention to be screened and Gummersbach a nearly significant decrease. The meta-analysis of the RCTs showed a significant decrease in the intention to be screened, $7 \%, 95 \%$ CI $(2 \%$ to $15 \%)$ (table A3.2, online supplementary appendix 3). The lower proportions intending to screen in the Mathieu study with respect to the other studies (table 3) can be attributed to the fact that women were younger than 50 , the recommended age for starting screening in Australia.

\section{DISCUSSION}

\section{Summary of main results}

This systematic review includes three RCTs and one before-after study assessing DAs given to women facing the decision to be screened with mammography. There was variability in the type and amount of information included in the DAs, and also in the information given to the control group. This variability may explain, in part, the significant heterogeneity in all the outcomes evaluated. Despite this heterogeneity, the meta-analysis revealed that DAs produce a statistically significant

\begin{tabular}{lllllc}
\hline Table 2 & Description of studies' participants & & & \\
\hline Study & Group & Participants & Age mean (SD) & Previous mammography & University degree \\
\hline Mathieu et al $^{24}$ & Intervention & 172 & $41.9(2.0)^{*}$ & $53(30.8 \%)$ & $76(44.2 \%) \dagger$ \\
& Control & 212 & $41.8(2.2)^{*}$ & $52(24.5 \%)$ & $126(59.4 \%) \dagger$ \\
Eden et al ${ }^{25}$ & Before-after & 75 & $45.0(2.5)$ & $51(68.0 \%)$ & $34(45.3 \%)$ \\
Gummersbach et al ${ }^{20}$ & Intervention & 178 & $48.67(0.79)$ & $\ddagger$ & $33(18.5 \%)$ \\
& Control & 175 & $48.76(0.80)$ & $\ddagger$ & $23(13.2 \%)$ \\
Hersch et al ${ }^{11}$ & Intervention & 419 & $49.67(0.44)$ & $\S$ & $119(28.4 \%)$ \\
& Control & 419 & $49.70(0.44)$ & $\S$ & $123(29.4 \%)$ \\
\hline
\end{tabular}

*Out of the assessed participants, 116 and 198 in intervention and control groups, respectively. tOut of the assessed participants, 114 and 199 in intervention and control groups, respectively. $\ddagger$ Three and four women with breast cancer in intervention and control groups, respectively. Participants were not asked about mammographic exams in the past.

$\S$ No women with previous mammogram in the previous 2 years but it is not stated how many women had mammograms more than 2 years before being included in the study. 
Table 3 Risk differences for the dichotomous outcomes: informed choice, knowledge, positive attitudes/values towards screening, undecided and intention to be screened

\begin{tabular}{|c|c|c|c|c|c|}
\hline Outcome & Study & Group & Assessed & n (\%) & Difference, $p$ value ${ }^{*}$ \\
\hline \multirow[t]{4}{*}{ Informed choice $\dagger$} & Mathieu et $\left.a\right|^{24} \ddagger$ & Intervention & 112 & 65 (58.0\%) & $21.5 \%, p<0.001$ \\
\hline & & Control & 192 & $70(36.5 \%)$ & \\
\hline & Hersch et $a l^{11} \S$ & Intervention & 409 & $99(24.2 \%)$ & $8.8 \%, p=0.0017$ \\
\hline & & Control & 408 & $63(15.4 \%)$ & \\
\hline \multirow[t]{4}{*}{ Knowledge } & Mathieu et $\left.a\right|^{24} \emptyset$ & Intervention & 113 & $106(93.8 \%)$ & $10.7 \%, p=0.01$ \\
\hline & & Control & 189 & $157(83.1 \%)$ & \\
\hline & Hersch et $a l^{11 \star \star}$ & Intervention & 419 & $122(29.1 \%)$ & $13.0 \%, p<0.001$ \\
\hline & & Control & 419 & $71(16.9 \%)$ & \\
\hline \multirow[t]{4}{*}{ Positive attitudes $† \dagger$} & Mathieu et al ${ }^{24}$ & Intervention & 111 & $88(79.3 \%)$ & $0.2 \%, p=0.89$ \\
\hline & & Control & 182 & $144(79.1 \%)$ & \\
\hline & Hersch et $\mathrm{al}^{11}$ & Intervention & 409 & $282(68.9 \%)$ & $-14.4 \%, p<0.001$ \\
\hline & & Control & 408 & $340(83.3 \%)$ & \\
\hline \multirow[t]{4}{*}{ Undecided } & Mathieu et al ${ }^{24}$ & Intervention & 117 & $21(17.9 \%)$ & $-21.3 \%, p<0.001$ \\
\hline & & Control & 209 & $82(39.2 \%)$ & \\
\hline & Hersch et al ${ }^{11}$ & Intervention & 419 & $69(16.5 \%)$ & $9.3 \%, p<0.001$ \\
\hline & & Control & 419 & $30(7.2 \%)$ & \\
\hline \multirow[t]{8}{*}{ Intention to be screened } & Mathieu et $\left.a\right|^{24}$ & Intervention & 117 & $50(42.7 \%)$ & $3.0 \%, p=0.64$ \\
\hline & & Control & 209 & $83(39.7 \%)$ & \\
\hline & Eden et $a^{25}$ & Before & 75 & $54(72.0 \%)$ & $6.7 \% \neq \neq, p=0.123$ \\
\hline & & After & 75 & 59 (78.7\%)㧊 & \\
\hline & Gummersbach et $\left.a\right|^{20}$ & Intervention & 178 & $145(81.5 \%)$ & $-7.1 \%, p=0.06$ \\
\hline & & Control & 175 & $155(88.6 \%)$ & \\
\hline & Hersch et al ${ }^{11}$ & Intervention & 419 & $308(73.5 \%)$ & $-13.1 \%, p<0.001$ \\
\hline & & Control & 419 & 363 (86.6\%) & \\
\hline
\end{tabular}

*Fisher's exact test.

†Eden provided only a postintervention mean of the preparation for decision-making scale of 73.2 (18.1).

$\ddagger$ Out of the women assessed, including undecided women in the denominator.

$\S$ Informed choice defined as adequate knowledge and intentions consistent with attitudes.

ПKnowledge (according to Mathieu): score higher than 5 out of 10.

${ }^{\star \star}$ Knowledge (according to Hersch): adequate knowledge when scoring at least $50 \%$ of the total available marks, including at least one numerical mark, on all three screening outcome subscales (breast cancer mortality benefit, false-positive screening result and overdiagnosis). ††Positive attitudes/values $>50$ out of 100 according to Mathieu and $\geq 24$ out of 30 according to Hersch.

$\ddagger \ddagger D$ ifference as postintervention minus preintervention values.

improvement in knowledge of screening outcomes as well as a significant increase in the frequency of women making an informed choice. However, no significant effects were observed for decision conflict, decision confidence and positive attitudes towards screening. Therefore, the overall conclusion from our review is that DAs significantly increase women's knowledge and therefore the proportion of women making an informed choice, but do not significantly modify attitudes or intentions towards screening. It is important to mention that when the meta-analysis was performed on the RCT subgroup, we found a significant decrease in confidence in the decision and intention to be screened. This decrease in screening intention is consistent with the findings of Ivlev $e t a l^{26}$ in a recently published systematic review of the effect of DAs on women's intentions to undergo screening mammography in age groups where shared decision making is recommended.

Similarly, no significant effects were observed for the secondary outcomes that measured the frequency of participants remaining undecided or choosing to be screened. More specifically, Eden detected a significant decrease in intraindividual postintervention decision conflict, which was not observed by Hersch, when comparing women receiving a DA with overdiagnosis information versus those without it. Indeed, Eden also obtained a significant improvement in intraindividual postintervention decision confidence, while Gummersbach and Hersch obtained a significant decrease in decision confidence when comparing women receiving a DA with exhaustive information on screening adverse effects versus those without it. This result can be explained 
Table 4 Mean differences for the continuous outcomes: knowledge, decisional conflict and decisional confidence

\begin{tabular}{|c|c|c|c|c|c|}
\hline Outcome & Study & Group & $\mathbf{N}$ & Mean (SD) & Difference, $p$ value \\
\hline \multirow[t]{4}{*}{ Knowledge } & Mathieu et $a l^{24 *}$ & Intervention & 113 & $7.35(1.84)$ & $1.1, p<0.001$ \\
\hline & & Control & 189 & $6.27(1.85)$ & \\
\hline & & Control & 168 & $5.23(2.06)$ & \\
\hline & Hersch et $a l^{11} \dagger$ & Intervention & 419 & $13.49(4.36)$ & $1.65, p<0.001$ \\
\hline \multirow[t]{4}{*}{ Decisional conflict } & Eden et $a l^{25} \ddagger$ & Before & 75 & $46.33(27.04)$ & $-38.0, p<0.001$ \\
\hline & & After & 75 & $8.33(15.58)$ & \\
\hline & Hersch et $a l^{11}$ & Intervention & 419 & $12.55(17.60)$ & $0.35, p=0.78$ \\
\hline & & Control & 419 & $12.20(18.90)$ & \\
\hline \multirow[t]{4}{*}{ Decisional confidence } & Eden et $a l^{25} \S$ & Before & 75 & 79.67 (18.62) & 16.16, $p<0.001$ \\
\hline & & Control & 182 & $5.52(0.93)$ & \\
\hline & Hersch et $a l^{11 \star *}$ & Intervention & 419 & $4.35(0.74)$ & $-0.18, p=0.0003$ \\
\hline & & Control & 419 & $4.53(0.67)$ & \\
\hline
\end{tabular}

${ }^{*}$ Knowledge scored, range $0-10$.

†Knowledge scored, range 0-22.

‡Decision conflict scale, range 0-100.

$\S$ Self-efficacy scale, range 0-100.

१Confidence scale, range 0-6.

${ }^{\star *}$ Confidence scale, range $0-5$ (mean of 3 subscales).

by the impact of the information on adverse events of screening. Positive attitudes towards screening significantly decreased when overdiagnosis information was added to the DA, as observed by Hersch, in contrast with the absence of change observed by Mathieu. The frequency of women remaining undecided after DAs showed completely contradictory results. While Mathieu observed a very significant decrease, Hersch obtained a significant increase. The frequency of women decided to be screened showed a significant difference in the Hersch study, where a decrease was observed for the group provided with overdiagnosis information, while Gummersbach, the other study incorporating thorough information on mammography adverse effects, showed a nearly significant decrease.

\section{Quality of the evidence}

Risk of bias ratings shows that the included studies had a low risk of bias in most of the assessed domains. There may have been publication bias due to failure to report negative findings. Several of the outcomes showed a high level of heterogeneity that limits the interpretation of the pooled effect size.

\section{Strengths and limitations}

This is the first systematic review focused on the impact of DAs about BC screening on informed choice and other relevant outcomes from the women's perspective. Our review focused on studies that assess DAs designed to inform and help women to decide, not on studies aimed at encouraging participation and adherence.

Studies differed in design, especially in terms of the control group. In the Mathieu et al study, ${ }^{24}$ the control group did not receive the DA until the outcome measures had been completed. The Eden et al study ${ }^{25}$ assessed the postintervention intraindividual changes after the DA was provided. In the Gummersbach et al study, ${ }^{27}$ a more informative leaflet was compared with a less informative one. Finally, in the Hersch et al study, ${ }^{11}$ the intervention DA had evidence-based explanatory and quantitative information on overdiagnosis, BC mortality reduction and false positives, whereas the control DA included information on BC mortality reduction and false positives. Previous knowledge was not measured in the Mathieu and Gummersbach RCTs, although one expects that both groups had similar knowledge about mammography screening at baseline. Hersch et $\mathrm{l}^{11}$ measured some basic knowledge at baseline using a subset of items and showed similar results between groups. In the Eden study, which assessed intraindividual changes, the DA was particularly useful for the least informed and least confident women. On the other hand, Gummersbach et $a l^{20}$ noted that education level was positively associated with acquired knowledge and that the less educated women had less relevant decisional knowledge after reading the leaflet, but they were more willing to undergo mammography than more educated women. Only the Hersch study 


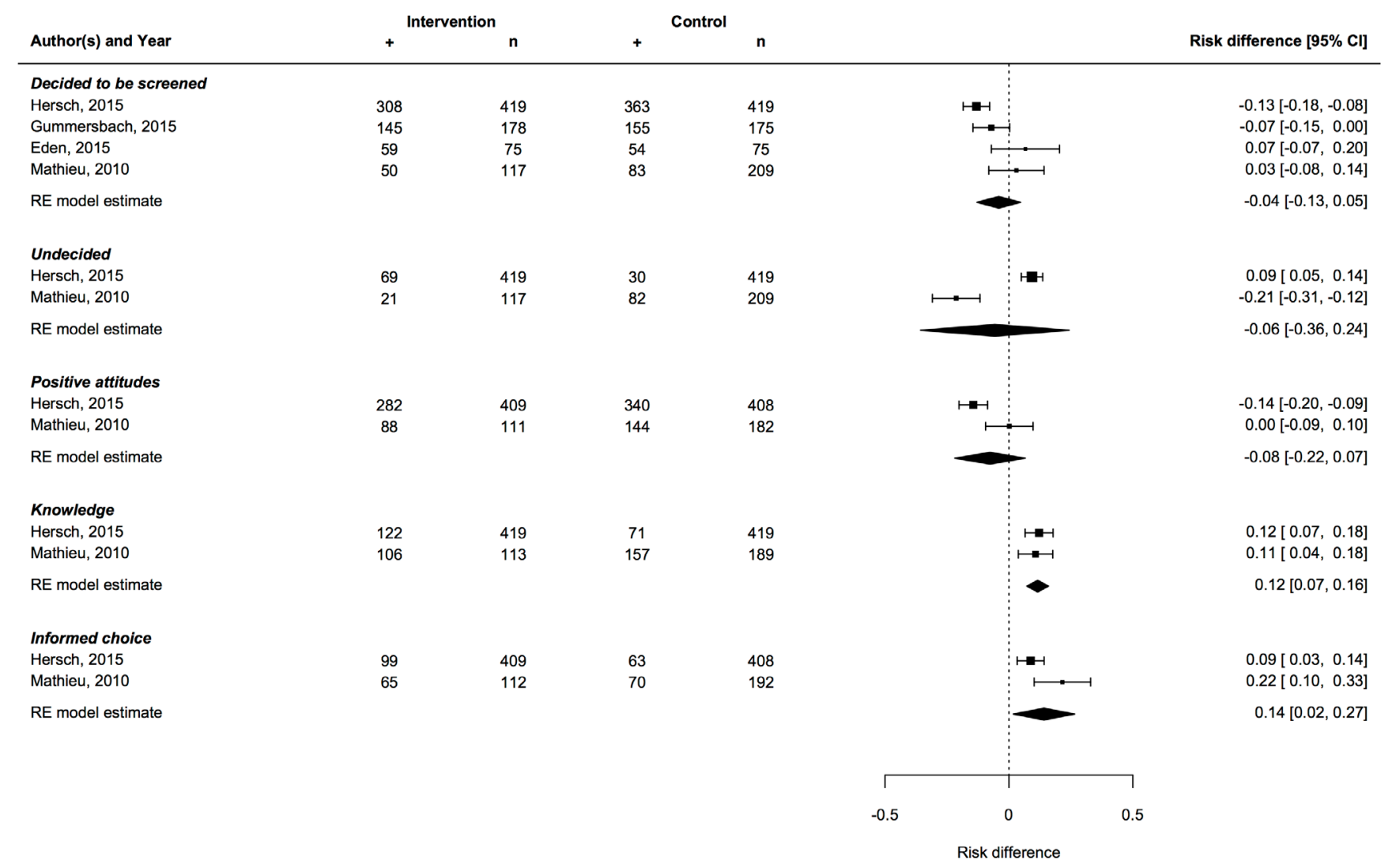

Figure 2 Meta-analysis of risk differences for the dichotomous outcomes (random effects (RE) model). Heterogeneity measures: informed choice: $I^{2}=74.7 \%, Q$ test $p=0.047$; knowledge: $I^{2}=0 \%, Q$ test $p=0.75$; positive attitudes: $I^{2}=84.6 \%, Q$ test $p=0.011$; undecided: $I^{2}=96.9 \%, Q$ test $p<0.001$; intention to be screened: $I^{2}=75.9 \%, Q$ test $p=0.008$.

included a follow-up for final screening participation, but the results are not published yet.

The limitations of the study are principally related with the generalisation of the results. Women included in the studies probably had a higher education level, greater health awareness and were more actively involved in healthcare decisions than women in the general population. In addition, the DAs were designed using specific data from Australia (Mathieu and Hersch), the USA (Eden) and Germany (Gummersbach), providing results which may not be generalisable to other countries. All studies evaluated the DAs only from the women's perspective, and in the context of research, where participants may have a higher level of commitment than women invited to participate in a breast screening programme.

\section{Unanswered questions and future research}

Women should use DAs to be informed and support their decisions about $\mathrm{BC}$ screening given their preferences and attitudes. It is important to ensure that the information provided is well understood by all women, including those with lower level of education.

The internet is an inexpensive tool for the dissemination of DAs or to provide additional information, if necessary, in order to present women with all the options available and the harms and benefits of each of them. But there are women who are not familiarised with or do not have access to the internet and therefore other ways to disseminate information are also needed.

According to Gummersbach, the doctor's advice was the most important factor helping with the decision to be screened for almost half of the women. This result indicates the importance of shared decision making, where DAs are essential tools. Shared decision making can also help reduce decisional conflict and improve confidence when information on screening harms is provided. In our search, we found 17 papers that described interventions to increase uptake compared with 4 studies designed to increase knowledge about the benefits and harms of the intervention. Given that the search was not designed to identify studies with 'increased uptake', this finding adds information to the important debate about medical ethics in relation to screening interventions-basically the old-fashioned paternalistic attitude versus citizen involvement and shared decision making.

As highlighted by Hersch $e t$ al, establishing what constitutes an informed choice, and what knowledge is needed in order to be informed, is an important issue and no consensus currently exists on what knowledge constitutes being objectively informed enough for an informed or shared decision. When Hersch et al used an expert-led approach based on medical guidelines and underpinned by decision theory, which required numerical 
Intervention Control

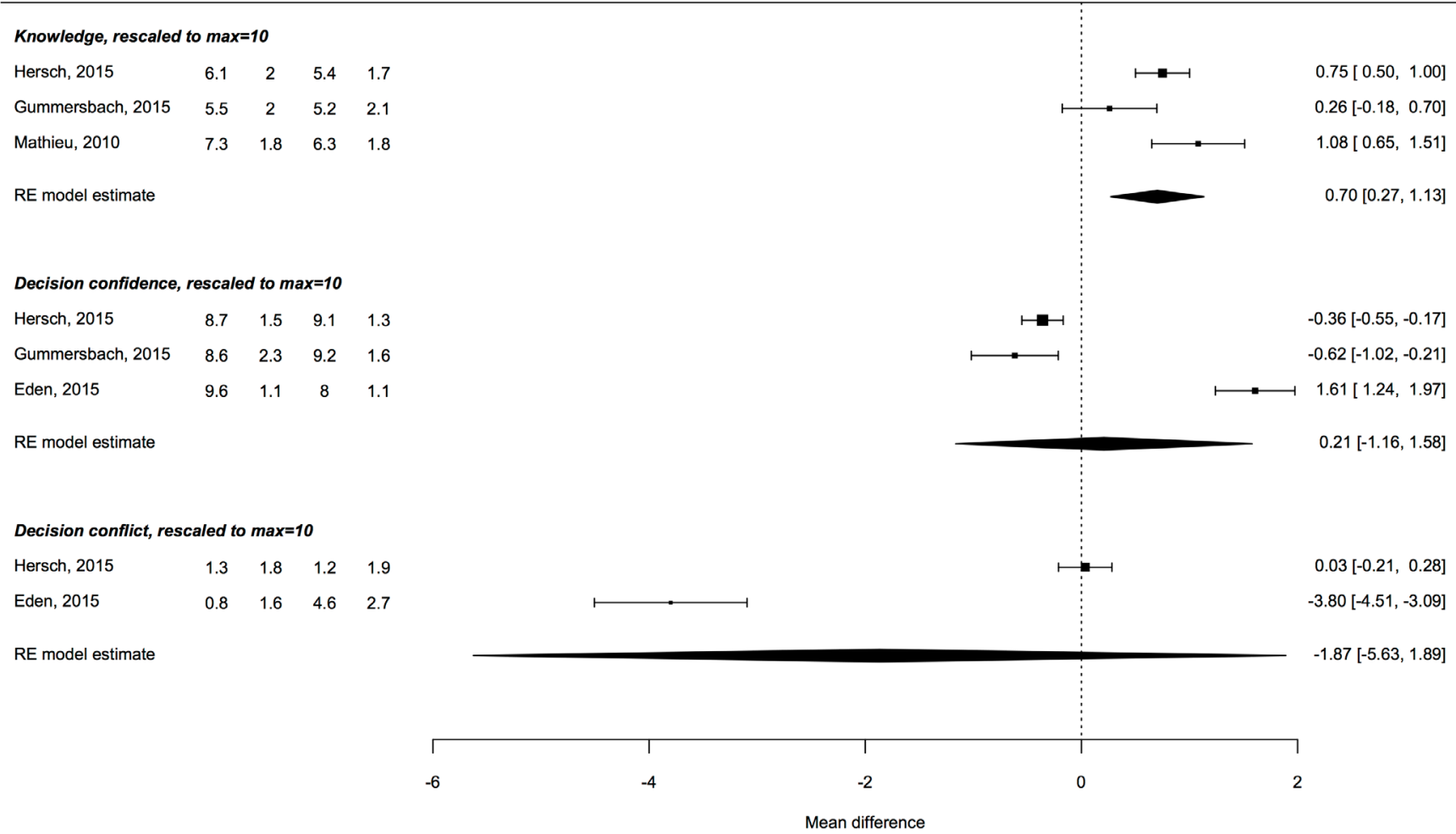

Figure 3 Meta-analysis of mean differences in scores for the quantitative outcomes (random effects (RE) model). Heterogeneity measures: decision conflict: $I^{2}=99.0 \%$, $Q$ test $p<0.001$; decision confidence: $I^{2}=98.3 \%, Q$ test $p<0.001$; knowledge: $\mathrm{I}^{2}=75.7 \%, \mathrm{Q}$ test $\mathrm{p}=0.030$.

and conceptual knowledge, only $24 \%$ in the intervention group and $15 \%$ in the control group were assessed as informed. When only conceptual knowledge was required, these proportions increased to $50 \%$ and $19 \%$, respectively. Difficulties understanding quantitative information or the widespread positive value placed on cancer screening can produce a certain resistance to information on possible harms. Their study was the only one obtaining a significant increase in the amount of women remaining undecided about being screened in the group receiving information on overdiagnosis.

The DAs of the included studies lacked detailed information on the outcomes of screening, detection, treatment, or financial strain and opportunity costs from the perspective of the society, which could be considered important for inclusion in future DAs.

\section{CONCLUSIONS}

DAs for BC screening can improve knowledge and promote informed decision making, in accordance with their preferences, for women who face the decision of screening. However, we found divergent results on decisional conflict and decision confidence. Under the new paradigm, which favours informed choice rather than maximising uptake, more research is necessary for the improvement of DA.
Acknowledgements We thank Dr Karen Eden and Dr Jolyn Hersch for facilitating non-published data that enabled us to obtain summary measures of some outcomes in the performed meta-analyses, and Krystal A Klein, PhD, for her support in the Eden study data. We are indebted to Ivan Solà, from the Iberoamerican Cochrane Centre, for performing the search in the EMBASE, PsycINFO and CINAHL databases. We also thank Maria Feijoo-Cid, PhD, and the manuscript reviewers for their insightful comments to the previous version of the manuscript, and JP Glutting for review and editing.

Contributors MMA, MCL and MR designed the study. All authors contributed towards the execution of the study. MMA provided methodological expertise in systematic reviews and searching strategies. The selection and risk of bias assessment of each study was independently conducted in pairs by four reviewers (MCL, MJPL, MMA and MR). APR contributed to extracting the information of the identified studies and assessing the inclusion criteria. MMA and MR wrote the first draft with guidance and contributions from MCL, MJPL and MG. All authors read, provided critical feedback and approved the final manuscript.

Funding This study was supported by the research grant 'Women participation in decisions and strategies on early detection of breast cancer' (PI14/00113) from the Instituto de Salud Carlos III and cofunded by Fondo Europeo de Desarrollo Regional (FEDER) 'Una manera de hacer Europa'. APR received a grant for PhD students from the Lleida Biomedical Research Institute (IRBLLEIDA). All authors declare funding from the Spanish Ministry of Health and the Biomedical Research Institute of Lleida (IRBLLEIDA).

Competing interests None declared.

Ethics approval The study was approved by the Ethics Committee of the Hospital Universitari Arnau de Vilanova in the city of Lleida (Spain).

Provenance and peer review Not commissioned; externally peer reviewed. Data sharing statement № additional data available.

Open Access This is an Open Access article distributed in accordance with the Creative Commons Attribution Non Commercial (CC BY-NC 4.0) license, which 
permits others to distribute, remix, adapt, build upon this work non-commercially, and license their derivative works on different terms, provided the original work is properly cited and the use is non-commercial. See: http://creativecommons.org/ licenses/by-nc/4.0/

(C) Article author(s) (or their employer(s) unless otherwise stated in the text of the article) 2017. All rights reserved. No commercial use is permitted unless otherwise expressly granted.

\section{REFERENCES}

1. Rutqvist LE, Miller A, Andersson I, et al. Reduced breast-cancer mortality with mammography screening-an assessment of currently available data. Int J Cancer 1990;S5:76-84.

2. Gøtzsche PC, Olsen O. Is screening for breast cancer with mammography justifiable? Lancet 2000;355:129-34.

3. Berry DA, Cronin KA, Plevritis SK, et al. Effect of screening and adjuvant therapy on mortality from breast cancer. $N$ Engl $J$ Med 2005;353:1784-92.

4. Siu A US. Preventive Services Task Force. Screening for breast cancer: USPSTF recommendation statement. Ann Intern Med 2016;164:279-96.

5. Nelson HD, Fu R, Cantor A, et al. Effectiveness of breast cancer screening: systematic review and meta-analysis to update the 2009 U.S. Preventive Services Task Force recommendation. Ann Intern Med 2016;164:244-55.

6. Marmot MG, Altman DG, Cameron DA, et al. The benefits and harms of breast cancer screening: an independent review. Br J Cancer 2013;108:2205-40.

7. Gotzsche PC, Jorgensen KJ. Screening for breast cancer with mammography. Cochrane Database Syst Rev 2013;6:CD001877.

8. Nelson HD, Pappas M, Cantor A, et al. Harms of breast cancer screening: systematic review to update the 2009 U.S. Preventive Services Task Force recommendation. Ann Intern Med 2016;164:256-67.

9. Stefanek ME. Uninformed compliance or informed choice? A needed shift in our approach to cancer screening. J Natl Cancer Inst 2011;103:1821-6.

10. Strech D. Participation rate or informed choice? Rethinking the European key performance indicators for mammography screening. Health Policy 2014;115:100-3.

11. Hersch J, Barratt A, Jansen J, et al. Use of a decision aid including information on overdetection to support informed choice about breast cancer screening: a randomised controlled trial. Lancet 2015;385:1642-52.

12. Moynihan R, Nickel B, Hersch J, et al. Public opinions about overdiagnosis: A national community survey. PLoS One 2015;13:1.

13. Vilaprinyo $E$, Forné $C$, Carles $M$, et al. Cost-effectiveness and harmbenefit analyses of risk-based screening strategies for breast cancer. PLoS One 2014;9:e86858.
14. Schousboe JT, Kerlikowske K, Loh A, et al. Personalizing mammography by breast density and other risk factors for breast cancer: analysis of health benefits and cost-effectiveness. Ann Intern Med 2011;155:10-20.

15. Ayer T, Alagoz O, Stout NK. OR Forum-A POMDP approach to personalize mammography screening decisions. Oper Res 2012;60:1019-34.

16. Evans DG, Astley S, Stavrinos P, et al. Improvement in risk prediction early detection and prevention of breast cancer in the NHS Breast Screening Programme and Family History Clinic: a dual cohort study. Southampton (UK): NIHR Journals Library: Programme Grants for Applied Research, No. 4.11; 2016.

17. Wu YY, Yen MF, Yu CP, et al. Individually tailored screening of breast cancer with genes, tumour phenotypes, clinical attributes, and conventional risk factors. Br J Cancer 2013;108:2241-9.

18. Stacey $D$, Légaré $F$, Lewis $K$, et al. Decision aids for people facing health treatment or screening decisions. Cochrane Database Syst Rev 2017:D001431.

19. Dreier M, Borutta B, Seidel G, et al. Communicating the benefits and harms of colorectal cancer screening needed for an informed choice: a systematic evaluation of leaflets and booklets. PLoS One 2014;9:e107575.

20. Gummersbach E, in der Schmitten J, Mortsiefer A, et al. Willingness to participate in mammography screening: a randomized controlled questionnaire study of responses to two patient information leaflets with different factual content. Dtsch Arztebl Int 2015;112:61-8.

21. National Institutes of Health. Quality Assessment Tool for before-after (pre-post) studies with no control group. Study Quality Assessment Tools. https://www.nhlbi.nih.gov/health-pro/guidelines/in-develop/ cardiovascular-risk-reduction/tools/before-after

22. Moher D, Liberati A, Tetzlaff J, et al. PRISMA Group. Preferred reporting items for systematic reviews and meta-analyses: the PRISMA statement. Int J Surg 2010;8:336-41.

23. R Core Team. R: A language and environment for statistical computing. R Foundation for Statistical Computing. Vienna, Austria, 2017. https://www.R-project.org/.

24. Mathieu E, Barratt AL, McGeechan K, et al. Helping women make choices about mammography screening: an online randomized trial of a decision aid for 40-year-old women. Patient Educ Couns 2010;81:63-72.

25. Eden KB, Scariati $\mathrm{P}$, Klein K, et al. Mammography decision aid reduces decisional conflict for women in their forties considering screening. J Womens Health 2015;24:1013-20.

26. Ivlev I, Hickman EN, McDonagh MS, et al. Women's change in intention to undergo screening mammography after using a patient decision aid: a systematic review and meta-analysis. J Gen Intern Med 2017.

27. Gummersbach E, in der Schmitten J, Abholz HH, et al. Effects of different information brochures on women's decision-making regarding mammography screening: study protocol for a randomized controlled questionnaire study. Trials 2013;14:319. 